\title{
Sou o sonho de humanidade que vocês esquecem: uma análise interseccional das opressões a partir da poesia de Ana Mendes
}

I am the dream of humanity that you forget: an intersectional analysis of oppressions from the poetry of Ana Mendes

\author{
Elisiane Santos de Matos \\ Universidade Estadual de Santa Cruz - UESC - Ilhéus - Bahia
}

\section{Sandra Maria Pereira do Sacramento}

Universidade Estadual de Santa Cruz - UESC - Ilhéus - Bahia

Resumo: O presente artigo trata da necessária revisão do cânone literário sob uma perspectiva interseccional, a partir da realização de rasuras no campo da representação. Defende-se o feminismo contemporâneo como um movimento de agência, apontando a intervenção política como uma de suas principais dimensões, a partir do lugar de fala. Promove-se, assim, a autorrepresentação das mulheres lésbicas escritoras, que por muito tempo foram relegadas ao lugar da não representação. Como corpus literário, elege-se o poema sem título de Ana Mendes, mulher sul-americana e lésbica, através do qual se intenta analisar a pertinência de se compreender os atravessamentos, nas representações do presente, dos seres subalternizados e, portanto, desviantes da norma na dinâmica da sociedade branca cisheteropatriarcal. Para tanto, utiliza-se como arcabouço teórico: Butler (20170, Schmidt (2017), Spivak (2010), Berth (2017), Ribeiro (2018), entre outros.

Palavras-chave: Cânone literário; Escritoras lésbicas; Feminismo lésbico; subalternização.

\begin{abstract}
This article revolves around the necessary revision of the literary canon from an intersectional perspective, with erasures regarding the concept of representation. It defends contemporary feminism as an agency movement, pointing out political intervention as one of its main dimensions, when we consider standpoints. It thus promotes the self-representation of lesbian women writers, who for a long time were relegated to the place of non-representation. As literary corpus, the untitled poem of the poet Ana Mendes, a South American and lesbian woman, is chosen; through which an attempt is made to analyse the pertinence of understanding the crossings in the representations of the present, of subalternized beings and, therefore, deviant from the norm in the dynamics of white cisheteropatriarchal society. For that purpose, Butler (2017); Schmidt (2017); Spivak (2010); Berth (2017); Ribeiro (2018); among others are used as theoretical framework.
\end{abstract}

Keywords: Literary canon; Lesbian writers; Lesbian feminism; subalternity.. 


\section{Introdução}

No texto de apresentação da obra de Profundanças (2017), intitulado Irmanades pelo grito, a organizadora Daniela Galdino afirma que Profundanças $2^{1}$ é um encontro de vozes dissidentes. Dito de outro modo, as mulheres publicadas em Profundanças2, - coletânea de onde é retirado o poema sem título de Ana Mendes, foco de análise do presente artigo- têm histórias e percursos individuais distintos; entretanto, carregam em comum o fato de estarem à margem das representações realizadas pela sociedade branca e cisheteronormativa ocidental, bem como pelo feminismo dito universal.

O feminismo contemporâneo tem sido apontado como um movimento de agência, e a intervenção política constitui uma de suas principais bandeiras. Ao incidir sua linha de força na denúncia à ausência de representação, no contexto anterior de luta de mulheres, ressalta a tamanha invisibilidade das mesmas no quesito: políticas públicas satisfatórias, voltadas ao enfrentamento da violência e à proteção da vida, com a consequente efetivação dos direitos humanos das mulheres. Ribeiro (2018), muito consonante ao que pensa Butler (2017), sobre a polêmica existente entre política e representação, afirma:

A relação entre política e representação é uma das mais importantes do que diz respeito à garantia de direitos para as mulheres, e é justamente por isso que é necessário rever e questionar quem são esses sujeitos que o feminismo estaria representando. Se a universalização da categoria "mulheres" não for combatida, o feminismo continuará deixando muitas delas de fora e alimentando assim as estruturas de poder (RIBEIRO, 2018, p. 47).

A problemática dos essencialismos gerou diversos embates internos ao movimento feminista, justamente por negligenciar demandas de vários segmentos de mulheres, que combinavam duas ou mais formas de opressão, em nome de pautas ditas universais, o que levou o feminismo pós-moderno a se perguntar "(...) até que ponto o esforço para localizar uma identidade comum como fundamento para uma política feminista impede uma investigação radical sobre as construções e as normas políticas da própria identidade?"(BUTLER, 2017, p. 10).

Ainda segundo Butler (2017), é tarefa do feminismo pós-moderno colocar sob questionamento as construções ontológicas de identidade dentro do próprio movimento feminista, a fim de pensar mecanismos capazes de promover uma plena representação dos sujeitos, tanto na linguagem, como na política, haja visto que:

(...) 0 sujeito feminista se revela discursivamente constituído, e pelo próprio sistema político que supostamente deveria facilitar sua emancipação, o que se tornaria politicamente problemático, se fosse possível demonstrar que este sistema produz sujeitos com traços de gênero determinados em conformidade com um eixo diferencial de dominação, ou os produz presumivelmente masculinos. Em tais casos, um apelo acrítico a esses sistemas em nome da emancipação das "mulheres" estaria inelutavelmente fadado ao fracasso (BUTLER, 2017, p. 19).

Ao pressuporem que a escrita se constitui em uma das formas de luta pela libertação da mulher, ao questionarem o porquê da não representação, ao mesmo tempo em que buscam, a partir dos seus escritos, desconstruir estereótipos- estas mulheres denotam possuírem algum nível de empoderamento, ao passo que intentam fazer com que suas ideias e reflexões reverberem em outros corpos - o que mostra, na prática deste tipo de militância, um diálogo bastante presente com a ideia de movimentos cíclicos existentes nos processos de empoderamento, conceito que será analisado mais à frente neste texto.

Ainda no texto de apresentação da obra, Galdino (2017) faz alusão ao formato de roda, ao se referir ao encontro de mulheres em Profundanças2, o que leva também ao movimento giratório - que reitera a associação entre a maneira como estas mulheres se organizam e o movimento cíclico proposto para o empoderamento feminino:

Mais do que soma, aqui importa o encontro de vozes dissidentes, pois das vivências cotidianas temos retirado a matéria da reexistência nos lugares onde estamos - e não para onde nos predestinam. Vias sinuosas, veredas interrompidas e reinventadas nos colocaram em convergência. Novamente a roda se faz e nela projetamos sussurros que se expandem até reverberar em outros corpos. 
Agora já estamos irmanades pelo grito (GALDINO, 2017, p. 7).

Nota-se também que a organizadora escreve utilizando a primeira pessoa do plural, incluindo-se entre as mulheres cujas produções ela organiza, haja vista que poemas da professora mestra da UNEB, escritora e performer também fazem parte da coletânea. No entanto, acredita-se que a utilização do pronome nós, nesse texto, Irmanades pelo grito, alcança ainda outro sentido: o de unir as vozes das mulheres publicadas ao universo maior composto pela pluralidade de identidades, que compõem o sujeito mulheres, no pós-feminismo. Além disso, Galdino (2017) utiliza o neologismo irmanades, fazendo referência ao verbo irmanar, ou seja, praticar o movimento empático e amoroso, criando laços de irmandade entre as mulheres - que tem consonância com o conceito de sororidade, bastante utilizado pelos feminismos pós-modernos.

Pode-se constatar, a partir da análise do texto de abertura da obra, bem como do objeto central de investigação, neste artigo, o poema de Ana Mendes que participa da coletânea, que Profundanças2é uma obra de resistência, que propõe a escrevivência como ponto de partida para a produção do texto literário. 0 que se conforma, em grande medida, com o que Schmidt (2017) pensa a respeito de se repensar a dinâmica social da literatura, para além da análise meramente estética:

\begin{abstract}
Repensar a dinâmica social da literatura de forma a preencher as lacunas entre o escrito e o vivido, compensado e o sentido, e abranger - leque de relações entre literatura e sociedade, ideologia e realidade, não é somente buscar a interpretação que destrua a ilusão formalistade que a literatura existe no mundo à parte, desvinculada da realidade, de como vivemos, de como queremos viver no mundo. Repensar é transformar a nossa percepção, é alargar as bases de nossa compreensão sobre a Literatura como um fenômeno social dentro de um contexto marcado pela hegemonia cultural de atitudes patriarcais (SCHMIDT, 2017, p. 67).
\end{abstract}

Essa aproximação temática entre a literatura e as vivências sociais - identificado em Profundanças2, especificamente a escrevivências de mulheres, num contexto social de dominação masculina, permite entender a literatura como um lugar de reflexão para a transformação social, haja visto que permite às perspectivas femininas um protagonismo, antes apenas vivenciado por homens brancos de classes privilegiadas - que amplia e diversifica os pontos de vista na escrita literária.

\section{VIDAS REVOLUCIONÁRIAS: A} IMPORTÂNCIA DO EMPODERAMENTO ENQUANTO DESESTABILIZADOR DO MODUS OPERANDI

O feminismo é um movimento que constrói a sua teoria à medida que vivencia suas práticas políticas e sociais, de modo que haja uma ação contínua de reflexão teórica aliada à criação de mecanismos capazes de combater as opressões sexistas. O processo de empoderamento é um dos mecanismos que ganha corpo teórico a partir da terceira onda do movimento como um prolongamento das vivências empreendidas ao longo da primeira e da segunda ondas. Cada mulher presente na coletânea Profundanças $2 e$, de modo geral, as mulheres que compõem o tecido social, encontram-se em níveis de empoderamento próprios. Isso ocorre porque se empoderar é um movimento individual, que busca na coletividade subsídios para que possa ocorrer, de maneira que, ninguém pode empoderar o Outro, mas é possível criar condições materiais para que o Outro produza seu empoderamento.

Em $\mathrm{O}$ que é empoderamento?, Joice Berth analisa o termo sob a ótica do pós-feminismo, tendo o feminismo negro como ponto de partida. Para tanto, a teórica busca as raízes etimológicas da palavra, fazendo uma correlação entre seu surgimento nos Estados Unidos e a criação do neologismo realizada no Brasil, a partir da Teoria da Conscientização pensada por Paulo Freire, denunciando a necessidade de se desenvolver a consciência crítica nos indivíduos oprimidos. Segundo Berth (2017), no contexto norteamericano, empower é um verbo que deriva do substantivo power:

Power é um substantivo da língua inglesa que significa basicamente habilidade ou permissão 
para que alguém realize alguma coisa. Também pode significar autoridade, força, entre outras coisas. Já a palavra empower, que de acordo com o Merriam-WebsterDictionary, um dos mais confiáveis dicionários online da América e que pertence à marca homônima já conhecida no mercado editorial, foi usada pela primeira vez em 1651, surgiu de uma adaptação específica do próprio idioma inglês chamadaverbing, que consiste em transformar um substantivo em verbo. Logo o significado ao pé da letra de empower é dar poder ou habilidade a algo ou a alguém (BERTH, 2017, p. 18).

Berth (2017) ainda traz o significado do termo empowerment, segundo o dicionário da Universidade de Cambridge, que coaduna com a significação dada por Rappaport, em 1977:

No Cambridge Dictionary, dicionário da Universidade de Cambridge, a palavra empowermenttem o seguinte significado: "o processo de ganhar liberdade e poder para fazer o que você quer ou controlar o que acontece com você". Da mesma forma, a palavra empoderamento, que, ao pé da letra, significa dar poder ou capacitar, termo cunhado pelo sociólogo estadunidense Julian Rappaport, em 1977. Para o sociólogo era preciso instrumentalizar certos grupos oprimidos para que eles pudessem ter autonomia (BERTH, 2017, p. 19).

No Brasil, grande parte da literatura a respeito do conceito de empoderamento afirma que este neologismo guarda inúmeras ligações com a teoria da conscientização, desenvolvida por Paulo Freire. Acredita-se que o pensamento freiriano,voltado às questões dos oprimidos,teria inspirado a ideia de empoderamento - o que não inviabiliza o argumento de que o conceito ganha força e prática social dentro do feminismo negro, como mostra Berth (2017):

No entanto, vale dizer, por outro lado, que diversas literaturas apontam 0 educador brasileiro premiado mundialmente e mais vezes citado no exterior, Paulo Freire, quando pensou na década de 60 sobre a Teoria da Conscientização, a qual inspirou a Teoria do Empoderamento, como veremos a partir de agora, como um dos precursores da análise aplicada em função da realidade de grupos oprimidos (BERTH, 2017, p. 26).

Nesse sentido, o ponto inicial do processo de empoderamentofreiriano estaria no despertar da consciência crítica no indivíduo. Ocorre que, na obra Quem tem medo do feminismo negro? Ribeiro (2018) aponta que esta ação individual é ultrapassada por um movimento que precisa e deve ser coletivo:

\begin{abstract}
Empoderamento implica uma ação coletiva desenvolvida pelos indivíduos quando participam de espaços privilegiados de decisões, de consciência social dos direitos. Essa consciência ultrapassa a tomada de iniciativa individual de conhecimentos e superação da realidade na qual se encontra. É uma nova concepção de poder que produz resultados democráticos e coletivos (RIBEIRO, 2018, p. 136).
\end{abstract}

Desse modo, é possível o argumento de que a associação confusa entre empoderamento e superação individual, dissociada de ações sociais estruturantes contra as opressões, funciona como um não rompimento com as estruturas opressoras. Pondose sobre a mulher a responsabilidade solo de se empoderar, retira-se do opressor a responsabilidade sobre o processo de subalternização do Outro, da coletividade a obrigação de promover mudanças, ao passo que provoca o esvaziamento de sentido do termo empoderamento. A análise de Berth (2017, p. 40) aponta que, entre outros enganos, o erro está em "julgar que se empoderar é transcender individualmente certas barreiras" (2017, p. 40), deixando de usar a "interseccionalidade" enquanto método de análise que propiciaria pensar empoderamento comoum conjunto de "estratégias necessariamente antirracistas, antissexistas e anticapitalistas" (2017, p. 40), o que não anularia a presença importante da dimensão individual do processo de empoderamento, posto que:

O empoderamento individual e coletivo são duas faces indissociáveis do mesmo processo, pois o empoderamento individual está fadado ao empoderamento coletivo, uma vez que uma coletividade empoderada não pode ser formada por individualidades e subjetividades que não estejam conscientemente atuando dentro de processos de empoderamento (BERTH, 2017, p. 42, grifo da autora). 
Nesse sentido, apesar de o movimento de empoderamento só possa ocorrer pela vontade do próprio indivíduo, Ribeiro (2018) sustenta a impossibilidade do olhar autocentrado de quem se empodera:

\begin{abstract}
O empoderamento não pode ser autocentrado, parte de uma visão liberal, ou somente transferência de poder. Vai além. Significa ter consciência dos problemas que afligem e criar mecanismos para combatê-los. Quando uma mulher se empodera, tem condições de empoderar outras (RIBEIRO, 2018, p.136).
\end{abstract}

Então, o processo de empoderamento, embora tenha sua realização de maneira individual, ou seja, cada indivíduo, promovendo seu próprio empoderamento, só ocorrerá de maneira efetiva, caso seja alimentado por medidas que toquem a coletividade, de modo a desestabilizar o modus operandi. Caso contrário, seria uma luta individual contra toda uma estrutura que ainda se mantém seguindo a lógica do opressor. Ribeiro (2018) aborda esta problemática do individual e coletivo no contexto do empoderamento, atentando também para a má interpretação que dá origem ao problema:

\begin{abstract}
O termo "empoderamento" muitas vezes é mal interpretado. Por vezes é entendido como algo individual ou a tomada de poder para se perpetuar opressões. Para o feminismo negro, possui um significado coletivo. Trata-se de empoderar a si e aos outros e colocar as mulheres como sujeitos ativos da mudança (RIBEIRO, 2018, p. 135).
\end{abstract}

A impossibilidade do olhar autocentrado se justifica na existência de movimentos cíclicos nos processos de empoderamento, "o movimento de recuperação da consciência do seu eu social, de suas implicações e agravantes" (BERTH, 2017, p. 41) de um grupo de mulheres possibilita alterações individuais e coletivas, na medida em que estas mulheres passarão a pensar e propor alterações coletivas, a partir dos seus respectivos loci sociais, possibilitando a criação de ambientes favoráveis ao empoderamento de outros grupos, haja visto que, “(...) se a coletividade é o resultado da junção de muitos indivíduos que apresentam algum - ou alguns
- elementos em comum, é intrínseco que estamos falando de um processo que se retroalimenta continuamente" (BERTH, 2017, p. 41).

No que toca aos entraves impostos pela sociedade patriarcal ao efetivo empoderamento feminino, Schmidt (2017) mostra como a relação de poder estabelecida entre o primeiro e o segundo dos pares passa também pelos lugares do desejo feminino. Entretanto, ao ascender ao poder pelo domínio de sua sexualidade, a mulher ilumina, em contrapartida, a vulnerabilidade masculina:

O celebrado "poder feminino" é o poder colocado a serviço da ideologia que mistifica a condição de submissão e inferioridade da mulher. Como ser intimamente ligado ao ciclo da natureza, cujos processos naturais a colocam fora da esfera de compreensão e controle do homem, Ela é temida e negada. Sua sexualidade é destrutiva porque, sendo objeto de desejo, Ela traz à superfície a vulnerabilidade masculina (SCHMIDT, 2017, p. 43).

Resta claro que, apesar de ter ganho força teórica e prática a partir do feminismo negro, a ideia de empoderamento funciona como o tema transversal a todos os feminismos. Segundo o projeto pensado pelos feminismos pós-modernos, a atitude de se empoderar deve alcançar o maior número e as mais diversas mulheres, nos seus respectivos loci sociais. Desse modo, no que toca às mulheres lésbicas, como a poeta Ana Mendes, o processo de empoderamento é imprescindível, tanto no que se relaciona à luta contra o patriarcado, bandeira, aliás, da segunda onda, como nos embates enfrentados dentro do próprio movimento feminista (haja visto que o lesbianismo ainda não é respeitado por significativa parcela das feministas) e do movimento LGBTQA+.

\subsection{Lesbianismo e empoderamento: a busca pelo protagonismo}

Enquanto movimento, o feminismo lésbico surge a partir da segunda onda do feminismo (que inaugura a ideia de que o corpo pertence à mulher $\mathrm{e}$ que sua sexualidade é algo a ser explorado), no 
contexto do Movimento de Libertação das Mulheres - propondo ações transformadoras às relações entre os sexos - e do surgimento da perspectiva de um feminismo radical pretendendo um igualitarismo extremo entre homens e mulheres. No entanto, as bandeiras levantadas pelas mulheres lésbicas iam além da luta contra o patriarcado, posto que, por se relacionarem de maneira homoafetiva, elas também se contrapunham à heterossexualidade compulsória e ao binarismo impositivo - o que as traziam para 0 seio do movimento homossexual. Em contrapartida, as lésbicas ainda empreendiam fortes críticas aos objetivos falocêntricos do movimento homossexual, ou seja, não havia nos dois movimentos um lugar confortável para que as mulheres lésbicas pudessem se sentir representadas.Falquet (2009), no Dicionário crítico do feminismo, fala sobre o processo de constituição do lesbianismo:

O lesbianismo, como movimento social, aparece no final dos anos 60 no mundo ocidental e em diversas metrópoles do Sul, numa atmosfera bastante "revolucionária". Desenvolve-se vinculado à segunda onda do feminismo e ao movimento homossexual construído a partir das "rebeliões" de Stonewall , em 1969 (como resposta à provocação da polícia em bares homossexuais, hoje mundialmente célebres devido às manifestações de "orgulho lésbico e homossexual" ao estilo das paradas gay) (FALQUET, 2009, p. 123).

Desde seu nascimento, enquanto movimento, o feminismo lésbico priorizou, talvez visando a autopreservação, a propositura de separação para com os outros movimentos. No entanto, é preciso explicitar que, apesar do movimento separatista, as lésbicas sempre estiveram lado a lado, tanto do movimento feminista macro, como do movimento homossexual, claro que com as tensões próprias a uma agência política que já nasce radical. Segundo Louro (2018), a partir de 1975, quando emerge o Movimento de Libertação Homossexual no Brasil, a ideia de interseccionalidade já havia adentrado os estudos acerca da homossexualidade e as agendas dos diversos movimentos passam a se pluralizar. Ao contrário de alguns grupos, as lésbicas não viram na integração de diferentes pautas uma estratégia eficaz, ao invés disso, elegeram a separação como a melhor resolução no caminho de ter suas demandas priorizadas:

A agenda de luta também se pluraliza: para alguns o alvo é a integração social - a integração numa sociedade múltipla, talvez andrógina e poliforma; para outros (especialmente para as feministas lésbicas) 0 caminho é a separação - a construção de uma comunidade e de uma cultura próprias (LOURO, 2018, p. 29).

Talvez seja justamente por priorizarem o protagonismo dentro do movimento, que as mulheres lésbicas buscaram construir para si uma terminologia que as representasse de maneira mais coerente com suas identidades, pois, tanto o termo homossexual, quanto o termo gay servem para identificar tanto homem, quanto mulher - colocando no mesmo plano duas identidades, que ocupam espaços bastante diferentes no sistema patriarcal:

Além de poder ser utilizado ou reivindicado
para descrever práticas individuais de
mulheres, o termo "lesbianismo" se refere
também a um conjunto de abordagens teóricas
e movimentos sociais que problematizam
essas práticas. Globalmente, no sentido
político, o lesbianismo pode ser considerado
uma crítica em atos e um questionamento do
sistema heterossexual obrigatório de
organização social (FALQUET, 2009, p. 123).

Nesse sentido, para Wittig - teórica feminista da segunda onda, apontada como precursora da Teoria Queer - a lésbica é o único conceito que transcende a mulher, justamente pela recusa à heterossexualidade compulsória e ao binarismo impositivo. Para Butler (2017), na obra Problemas de Gênero:Feminismo e subversão da identidade, o fato de a lésbica se contrapor a esses valores mostra que eles ainda existem e têm pertinência. Louro (2018) corrobora com o pensamento de Butler e mostra esta relação de rechaço à norma como um caminho de mão dupla, na medida em que a linha de fronteira gerada pelas sexualidades desviantes expõe os processos de formação e conformação das normas cisheteropatriarcais: 
Paradoxalmente, ao se afastarem, fazem-se ainda mais presentes. Não há como esquecêlos. Suas escolhas, suas formas e seus destinos passam a marcar a fronteira e o limite, indicam o espaço que não deve ser atravessado. Mais do que isso, ao ousarem se construir como sujeitos de gênero e de sexualidade precisamente nesses espaços, na resistência e na subversão das "normas regulatórias", eles e elas parecem expor, como maior clareza e evidência, como essas normas são feitas e mantidas (LOURO, 2018, p. 1718).

Outra contraposição existente entre 0 pensamento de Wittig e as teóricas Queerda terceira onda do feminismo: Butler e Louro, no que concerne à eleição da lésbica como única possibilidade para a mulher transcender e, portanto, como um novo modelo estabelecido como ideal, é que construir novas identidades fixas e definir novas fronteiras não parecem ser a saída mais lúcida na luta contra a heteronormatividade e o binarismo impositivo. Em vez disso, em consonância com o pensamento butleriano, Louro (2018) propõe a fluidez inconstante como característica para as identidades de fronteira:

\begin{abstract}
Personagens que transgridem gênero e sexualidade podem ser emblemáticas da pósmodernidade. Mas elas não se colocam, aqui, como um nosso ideal de sujeito. Não se pretende instaurar um novo projeto a ser perseguido, não há intenção de produzir uma nova referência. Nada seria mais anti-pósmoderno. A visibilidade e a materialidade desses sujeitos parecem significativas por evidenciarem, mais do que outros, o caráter inventado, cultural e instável de todas as identidades. São significativos, ainda, por sugerirem concreta e simbolicamente possibilidades de proliferação e multiplicação das formas de gênero e de sexualidade (LOURO, 2018, p. 22).
\end{abstract}

Ao invés de propor um novo modelo, mais uma especificidade, estabelecendo mais uma norma, no mesmo sentido do que pensa Butler, Louro (2018) opta por entender estas novas identidades desviantes como desestabilizadoras de certezas e provocadoras de novas percepções. Collin (2009) acredita que a criação de uma especificidade, bem como sua categorização, abre espaço para o engendramento de hierarquias e subordinações, o que seria um desserviço aos estudos de gênero:
$\mathrm{Na}$ verdade, toda afirmação de especificidade ressuscita o espectro da complementaridade e corre risco de dar garantias à hierarquização: a especificidade das mulheres é uma produção social destinada a justificar a sua subordinação, seja como objetos sexuais através da longa história da "obrigação de heterossexualidade" (Mathieu, 1991), seja como mães, relegando-as à esfera doméstica e excluindo-as da esfera pública (COLLIN, 2009, p. 62-63).

De fato, numa sociedade androcentrada, as lésbicas promovem um novo paradigma a ser investigado, haja visto que mulheres com relações homoafetivas renunciaram aos seus lugares de submissão nas relações heterossexuais, bem como, da regra da feminilidade imposta às mulheres, para vivenciarem outras formas de ser e se relacionar com o seu desejo. Relações afetivas e sexuais lésbicas desmantelam o modelo binário, que mantinha o caráter ilusório da autonomia masculina, posto que, ao contrário do que afirmava a sociedade patriarcal, nas relações mantidas sob o jugo da heterossexualidade compulsória, o homem precisa do segundo dos pares para exercer seu poder. Então, "o poder parecia ser mais do que uma permuta entre sujeitos ou uma relação de inversão constante entre um sujeito e um Outro; na verdade, o poder parecia operar na própria produção dessa estrutura binária em que se pensa o conceito de gênero" (BUTLER, 2017, p. 8).

Desse modo, a pertinência da articulação entre os outros segmentos do movimento feminista e as reivindicações das feministas lésbicas se justifica no olhar interseccional necessário ao pós-feminismo. Além do mais, ao ultrapassar a análise dicotômica proposta a partir dos modelos masculino/feminino, heterossexual/homossexual, os estudos de gênero dão um passo à frente, no sentido de teorizar as novas identificações de gênero, propondo uma "convergência política das perspectivas feministas, gays e lésbicas", transexuais não binários, etc. (BUTLER, 2017, p. 13).

\subsection{Sou o sonho de humanidade que vocês esquecem: uma análise interseccional das opressões a partir da poesia de Ana Mendes}


A jovem escritora de 22 anos, Ana Mendes é uma mulher lésbica, com poemas constantes de Profundanças2,que publicou as antologias CidaDelas(2017, Sebo Vermelho) e Blackout (no prelo) e participou do grupo de declamadores Dirocha, bem comoassina a fanpage Erro Errante, no Facebook, e o blog Pensamentos avulsos. Utiliza-se ainda de zine como forma de publicar seus escritos, como: Birgona, diário de um Cego; Prazer Pega Mate e Come e Terno.

No poema sem título, Ana Mendes escreve em primeira pessoa do singular, portanto, o lugar de fala é de uma mulher lésbica, embora a autora opte por também construir uma identidade múltipla ao longo do poema, que ao final, se transfigura numa charada, como se verá mais à frente, nesta análise. Ao assumir traços identitários diversos, à medida que vai descrevendo as opressões sofridas e, no percurso de construção do texto poético, a partir do olhar da mulher lésbica, a primeira pessoa do singular assume o lugar de mulheres heterossexuais, pessoas LGBTQIA+, pessoas pertencentes às classes menos favorecidas, sertanejos, moradores de rua, trabalhadores braçais etc. Além disso, as ambiências imaginadas pela poeta oscilam entre 0 Oriente do globo, as periferias e grandes centros urbanos do Brasil - pretendendo com isto alcançar a maior diversidade possível de perfis, que compreendem as minorias.

Pode-se constatar que a poesia analisada neste artigo é um texto de protesto e denúncia, posto que, Mendes (2017), por vezes, desafia os discursos hegemônicos, deixando evidenciadas as situações de vulnerabilidade, vivenciadas pelas mulheres, nas grandes metrópoles, nas regiões do semiárido brasileiro e no Oriente Médio, onde, além de sofrerem restrições sociais, religiosas e políticas, encontram-se imersas em vários conflitos e guerras.

O poema se mostra intervencionista, engajado e contestador, no que toca às temáticas voltadas aos seres subalternizados. É importante frisar que se trata do olhar de uma mulher sul-americana, lésbica, que, entre outros pontos, toca na situação de mulheres no Oriente, que sempre foi visto como o
Outro pela parte ocidental do globo, haja visto que, tudo o que não é Europa sofreu com os resultados da reificação produzida pelo sujeito europeu. Assim, se está diante do olhar de uma mulher brasileira subalternizada, que se detém também em outras mulheres, que passam pelo processo,como aquelas que habitam no Oriente, ou em seu próprio país de nascimento.

Neste sentido, a criação poética contribui para que sejam realizadas rasuras na história, a partir do olhar atento ao presente - definindo-o como consequência dos epistemicídios realizados ao longo da historiografia ocidentalizada, seja nos países colonizados da América, seja nos orientais. Acerca do processo de silenciamento epistêmico produzido pela Europa, no texto Pode o subalterno falar?, Spivak (2010) realiza uma importante reflexão sobre como a historiografia subalternizada:

A historiografia subalterna traz à tona questões de método que a impediram de usar tal artifício. Com respeito à "imagem" da mulher, a relação entre a mulher e o silêncio pode ser assinalada pelas próprias mulheres; as diferenças de raça e de classe estão incluídas nessa acusação. A historiografia subalterna deve confrontar a possibilidade de tais gestos. A restrita violência epistêmica do imperialismo nos dá uma alegoria imperfeita da violência geral que é a possibilidade de uma [nova] episteme [elaborada, a partir das margens] (SPIVAK, 2010, p.66).

A historiografia subalterna, de acordo com Spivak, promove as rasuras necessárias para o estabelecimento de um novo paradigma conceitual, mais diverso e multifacetado. Segundo Ribeiro (2018), por sua vez, em Quem tem medo do feminismo negro?, a busca por novas epistemologias já traz a ideia de interseccionalidade como metodologia e se sustenta na necessidade de entendimento de como ocorre a coexistência de grupos subalternizados:

Pensar novas epistemologias, discutir lugares sociais e romper com uma visão única não é imposição - é busca por coexistência. Ao quebrar a máscara, estamos atrás de novas formas de sociabilidade que não sejam pautadas pela opressão de um grupo sobre outro. Ao pensar o debate de raça, classe e gênero de modo indissociável, as feministas 
negras estão afirmando que não é possível lutar contra uma opressão e alimentar outra, porque a mesma estrutura seria reforçada (RIBEIRO, 2018, p. 26-27).

A máscara à qual se refere Ribeiro (2018) diz respeito à máscara do silenciamento descrita por Grada Kilomba (2019) no capítulo intitulado A máscara, do livro Memórias da plantação: episódios do racismo cotidiano:

Tal máscara foi uma peça muito concreta, um instrumento real que se tornou parte do projeto colonial europeu por mais de trezentos anos. Ela era composta por um pedaço de metal colocado no interior da boca do sujeito negro, instalado entre a língua e a maxilar e fixado por detrás da cabeça por duas cordas, uma em torno do queixo e a outra em torno do nariz e da testa. Oficialmente, a máscara era usada pelos senhores brancos para evitar que africanas/os escravizadas/os comessem canade-açúcar ou cacau enquanto trabalhavam nas plantações, mas sua principal função era implementar um senso de mudez e de medo, visto que a boca era um lugar de silenciamento e de tortura (KILOMBA, 2019, p. 33, grifos da autora).

Ainda sobre a violência epistêmica promovida pelo imperialismo, segundo Spivak (2010), ela é apenas um exemplo imperfeito da violência geral, que é possibilitada pela existência de apenas uma episteme, que é a do branco europeu, que tira a voz das minorias, que, no caso, pode ser exemplificado pela mulher, pelo negro, pelo índio, etc.

A seguir o poema na íntegra para posterior análise dos versos:

Sempre que resisto/ Sou arrastada, esfolada, pisoteada/ Espancada pelo punho do padrasto Capital/ Personificado na insígnia da farda/ Que sussurra em cassetetes e coronhadas:/ Recue!/ Desista!/ Os omissos se preenchem com mais um cheque/ Os desesperados com crack/ Ou esvaziam a cabeça com cleck!/ Afogam-me na lama/ Me bombardeiam no oriente/ Às vezes, caminho com um fuzil/ Que me pesa mais que meu corpo/ $\mathrm{E}$ a fome, minha companhia inseparável,/ Tem rosto franzido/ Com passos de brita caminha $\mathrm{E}$ sorri ao prato de comida:/ Quem dera/ Pelo menos aqueles alimentos cancerígenos/ Eu comesse.../ E o meu algoz?/ Assina e assassina/ Com mais um cheque/ tijolos/ E para me manter acordada/ Masco coca cheiro loló/ Caminho descalça/ Sobre pedregulhos e chão ressecado/ Com fome e sede/ Desesperada/ Também agonizo no concreto das metrópoles/ Nos morros, nos becos/ Morando entre lixão e bueiros Repouso pelas calçadas/ $E$ me esquento com a chama do isqueiro/ Seja no chão rachado/ Ou no asfalto/ Ou naquele terreno baldio/ Onde meu corpo abandonaram/ A mídia madrasta/ Ganhará mais um prêmio:/ Sonegação de impostos e um cheque/ Pelo registro fotográfico/ Da minha carcaça esquelética/ Apática, leiloa minha dor:/ Vende a imagem da minha tragédia/ Àqueles que Ihe querem/ Recortada, silenciosa e encoberta./ Lhes convido a responder a charada existencial:/ Quem eu sou?/ Sou o sonho de Humanidade/ Que vocês esquecem/ E perseguem (MENDES, 2017, p. 22)

Logo no primeiro verso do poema, Mendes (2017) traz a ação de enfrentamento: "Sempre que resisto", seguida de três adjetivos de conteúdo semântico que impactam o leitor, dando a ideia de atos de violência, em uma espécie de gradação na atrocidade desferida sobre o corpo da mulher: “arrastada, esfolada, pisoteada". E Alemany (2009) conceitua as violências sexistas, para o Dicionário crítico do feminismo:

As violências praticadas contra as mulheres devido ao seu sexo assumem múltiplas formas. Elas englobam todos os atos que, por meio de ameaça, coação ou força, Ihes infligem, na vida privada ou pública, sofrimentos físicos, sexuais ou psicológicos com a finalidade de intimidálas, puni-las, humilhá-las, atingi-las na sua integridade física e na sua subjetividade (ALEMANY, 2009, p. 271).

A despeito das palavras de Alemany, a fragilidade da mulher diante da agressão pode ser transformada pelo ato de resistir, pois,quem resiste, resiste a algo, com renúncia de si mesma, ou com enfrentamento; por isso, pode-se deduzir que, antes da resistência empreendida pelo eu enunciativo feminino, ainda houve outras ações opressoras. Outro termo importante à análise é o uso, no poema, do advérbio sempre, que imprime a ideia de que em nenhuma hipótese há uma ação mais pacificada do opressor: "Sempre que resisto/ Sou arrastada, esfolada, pisoteada/ Espancada pelo punho do padrasto Capital/ Personificado na insígnia da farda/ Que sussurra em cassetetes e coronhadas:/ Recue! / Desista!" (MENDES, 2017, p. 22).

Por ser um movimento emancipatório, a terminologia resistência se configura em uma das palavras de ordem do feminismo, seja no contexto da 
luta por direitos políticos e sociais da primeira onda, seja levando a bandeira do "pessoal é político" da segunda onda, com embates contra as violências sexistas, pela legalização do aborto e outras demandas, levantadas pela terceira onda do movimento. Para além dos confrontos externos, são reconhecidas relações de resistência dentro do próprio movimento feminista - o que faz com que, a cada objetivo alcançado, novas reivindicações ganhem evidência e inusitados enfrentamentos sejam necessários.

Até este ponto do poema, as brutalidades descritas por Mendes (2017) apresentam-se como violências físicas, mas nota-se no excerto: "Que sussurra em cassetetes e coronhadas:/ Recue! / Desista!", que elas têm uma intenção mais relacionada ao campo psicológico: a determinação de fazê-la recuar e desistir. Além disso, pode-se afirmar, em nível hipotético, que o sujeito que comete atos de violência, tem acesso a cassetetes e a armas (já que coronhadas figuram entre as formas de agressão expostas) e deve ser alguém de patente militar, algum policial, enfim, alguém das forças armadas.

Em seguida, Mendes (2017) faz nova referência ao uso de armas com a onomatopeia "cleck", para representar o som do disparo de um revólver. Ao tempo em que faz uso do jogo de sons com a palavra "crack" e "cleck": "Os omissos se preenchem com mais um cheque/ Os desesperados com crack/ Ou esvaziam a cabeça com cleck!/ Afogam-me na lama" (MENDES, 2017, p. 22).

No que se relaciona à omissão, pode-se estabelecer um linkentre o poema de Mendes (2017) com o pensamento de Ribeiro (2018), quando a autora se refere à omissão do Estado e a necessidade de a mulher negra munir-se deforça diante das adversidades, pois não tem com que contar.

Somos fortes porque o Estado é omisso, porque precisamos enfrentar uma realidade violenta. Internalizar a guerreira, na verdade, pode ser mais uma forma de morrer. Reconhecer fragilidades, dores e saber pedir ajuda são formas de restituir as humanidades negadas. Nem subalternizadas nem guerreira natural: humana. Aprendi que reconhecer as subjetividades faz parte de um processo importante de transformação (RIBEIRO, 2018, p. 20-21)

Imergindo o leitor num clima de violência, construído pela presença do verbo "bombardear", mas, dessa vez, trazendo um elemento novo: uma face das identidades representadas no poema aparece, neste momento, ao afirmar: "Me bombardeiam no oriente", a autora faz referência aos conflitos existentes no Oriente Médio. Ao tempo, que segue descrevendo o contexto de guerra vivenciado por estes povos, nos versos: "Às vezes, caminho com um fuzil/ Que me pesa mais que meu corpo" (MENDES, 2017, p. 22).

Mais à frente no poema, Mendes (2017) traz a imagem da fome, "companheira inseparável" do eu enunciativo, associando-a a características humanas, dando-lhe "rosto franzino e passos de brita" (significando que a fome caminha devagar) - o que conota certa fragilidade daquele que não se alimenta: "E a fome, minha companhia inseparável,/ Tem rosto franzido/ Com passos de brita caminha/ $\mathrm{E}$ sorri ao prato de comida:/ Quem dera/ Pelo menos aqueles alimentos / cancerígenos/ Eu comesse..."(MENDES, 2017, p. 22). Pode-se ressaltar, neste conjunto de versos, a crítica feita à produção alarmante de alimentos, com uso desenfreado de substâncias tóxicas pela indústria, que só visa ao lucro e pouco se importa com a saúde das pessoas, ao produzir alimentos, que levam ao adoecimento ou à morte nas pequenas e grandes cidades do país.

Denúncia que se confirma nos versos seguintes, pela junção de dois verbos com sonoridade, que remete ao eco: "Assina e assassina". Aliás, essa é uma característica presente no poema de Mendes (2017), a articulação entre palavras com sonoridade similar e significados complementares.Acredita-se que a autora faça uso desse recurso, com intuito de chamar atenção do leitor para as ações narradas ao longo do seu texto poético: "E o meu algoz? / Assina e assassina/ Com mais um cheque/ Aos meus sobram/ Crack e cleck!" (MENDES, 2017, p. 22). 
Ainda sobre os versos supracitados, Mendes (2017) volta a repetir as palavras "crack" e "cleck", mas, dessa vez, surgem dispostas lado a lado, o que confirma que há mesmo uma intenção poética de associar a camada fônica dos dois vocábulos ao sentido sugerido. Enquanto o "algoz" pratica o ato de assinar e assassinar seus entes próximos, restandoIhes somente o "crack" e o "cleck!", ou seja, o envolvimento com drogas ou a morte por arma de fogo. O que leva à ideia de que a autora coloca em lados opostos o opressor, que tanto assina como assassina, e os subalternizados, grupo do qual faz parte, haja visto o uso da expressão "aos meus sobram", denotando que o eu enunciativo se posiciona na resistência ao "algoz" (o opressor).

Em ato contínuo, a autora segue descrevendo o cotidiano de luta das classes proletárias do país: "Minhas mãozinhas carregam pedras/ Esculpem tijolos/ E para me manter acordada/ Masco coca cheiro loló/ Caminho descalça/ Sobre pedregulhos e chão ressecado/ Com fome e sede" (MENDES, 2017, p. 22). O diminutivo "mãozinhas" faz parecer queas atividades laborais de carregar pedras e esculpir tijolos são realizadas por uma criança - dedução que não se confirma pela mera interpretação literal do poema. Novamente, o uso de drogas é mencionado na obra, dessa vez a autora utiliza as palavras "coca" e "loló", como substâncias utilizadas pelos trabalhadores braçais, a fim de aplacar o cansaço e a fadiga.

Mendes (2017) continua a descrição das mais diversas formas de subalternização dos menos favorecidos, deixando evidenciada a dimensão classe, como uma das formas mais cruéis de subjugação das minorias:

Desesperada/ Também agonizo no concreto da metrópole/Nos morros, nos becos/ Morando entre lixão e bueiros/ Repouso pelas calçadas/ $\mathrm{E}$ me esquento com a chama do isqueiro/Seja no chão rachado/ Ou no asfalto/ Ou naquele terreno baldio/ Onde meu corpo abandonaram (MENDES, 2017, p. 22).

As mulheres descritas pela autora nos versos acima estão abaixo da linha de pobreza, numa situação de rua: "morando entre lixão e bueiros", repousando nas calçadas. Nestes versos, Mendes (2017) se refere às mulheres invisíveis nas grandes cidades. Abandonadas pela sociedade e pelo Estado, estas vivem na indigência e têm seus direitos humanos negados. São invisíveis aos transeuntes, como um reflexo do que representam para o restante das instituições.

"Desesperada", ela agoniza "no concreto das metrópoles" - esta mulher, cujo corpo é abandonado pelo Estado e pela sociedade, encontra-se numa alta condição de vulnerabilidade e violência, o que se confirma dos últimos versos: "Ou naquele terreno baldio/ Onde meu corpo abandonaram" - fazendo referência aos inúmeros casos de corpos assassinados e jogados em terrenos baldios de metrópoles brasileiras.

Em seguida, mais uma crítica é realizada por Mendes (2017), a saber, ao modo como a mídia se alimenta de maneira sensacionalista de tragédias cotidianas das grandes cidades: "A mídia madrasta/ Ganhará mais um prêmio:/ Sonegação de impostos e um cheque/ Pelo registro fotográfico/ Da minha carcaça esquelética/ Apática, leiloa minha dor:/ Vende a imagem da minha tragédia" (MENDES, 2017, p. 22).

Ao apontar para a corrupção existente entre os veículos midiáticos e o Estado, através da compra de posicionamentos e sonegação de impostos, Mendes (2017) qualifica a mídia como "madrasta" o que figurativamente significa dizer que ela é má, incapaz de gestos afetuosos e empáticos. O que se confirma nos versos seguintes, acerca da exposição sensacionalista do "registro fotográfico da carcaça esquelética", em troca de "um cheque e da sonegação de impostos". A "mídia madrasta" se mantém indiferente à dor e à situação de vulnerabilidade alheia, em troca de ganhos pecuniários.

No encerramento do poema, Mendes (2017) direciona o discurso para aqueles que consomem as mídias sensacionalistas, por meio de uma pergunta que qualifica como existencial: "Àqueles que lhe querem/ Recortada, silenciosa e encoberta. / Lhes convido a responder a charada existencial:/ Quem eu 
sou?" (MENDES, 2017, p. 22). Ao passo que ela mesma responde de pronto, matando a charada e levando o leitor à reflexão: "Sou o sonho de Humanidade/ Que vocês esquecem/ E perseguem".

\section{CONCLUSÃO}

Ana Mendes, no poema aqui analisado, ao fazer uso da escrita literária em forma de denúncia e resistência, promove empreendimentos atravessados pela interseccionalidade. Ao empreender o movimento de provocar rasuras, no sentido de desestabilizar a lógica estrutural do modus operandi, do racionalismo ocidental, o poema se posiciona, enquanto resistência às violências epistemológicas, psicológicas, físicas, entre outras, sofridas pelas mulheres negras, lésbicas, transexuais e demais minorias. Como consequência, promove a revisão do cânone literário oficial e empoderara-se pelo que diz e faz, a partir de seu lugar de fala. Nesse lócus enunciativo, denuncia as injustiças praticadas pelo Estado brasileiro e por outras sociedades, que negam cidadania e bemestar àqueles que estão à margem.

Com os dados pesquisados em Profundanças 2 e com os aportes teóricos trazidos nesta discussão, pode-se afirmar que urge desestabilizar as construções identitárias que mantêm o status quo, tendo em vista que a criação de estereótipos contribui para a banalização da violência sobre os corpos marginalizados, que, em dimensão estrutural, pavimenta 0 preconceito, situando, por exemplo, mulheres negras e transexuais em lugares de hipersexualização, homens negros nos lugares de criminalidade, criando barreiras para que tais identidades possam ocupar outros espaços, que não o reservado à invisibilidade das minorias.
Hidrata. Françoise Laborie. Hélène Le Doaré. DanièleSenoTier. São Paulo: Editora UNESP, 2009. p. 271-276.

BERTH, J. O que é empoderamento? Belo Horizonte: Letramento: Justificando, 2017.

BUTLER, J. Problemas de gênero: Feminismo e subversão da identidade. Tradução de Renato Aguiar. Rio de Janeiro: Editora Civilização Brasileira, 2017.

COLLIN, F. Diferença dos sexos (teorias da).Tradução de Vivian Aranha Saboia. In:HIDRATA, Helena; LABORIE, Françoise LE DOARÉ, Hélène; SENOTIER, Danièle (org).Dicionário Crítico do Feminismo.São Paulo: Editora UNESP, 2009. p. 5966.

FALQUET, J.F. Lesbianismo. Tradução: Francisco Ribeiro Silva Júnior. In: HIDRATA, Helena; LABORIE, Françoise LE DOARÉ, Hélène; SENOTIER, Danièle (org). Dicionário Crítico do Feminismo. São Paulo: Editora UNESP, 2009. p. 122- 128.

GALDINO, D. Irmandades pelo grito. In: GALDINO, Daniela (org.). Profundanças2. Ipiaú: Voo Audiovisual, 2017. p. 07.

KILOMBA, G. Memórias da Plantação: Episódios de Racismo Cotidiano. Tradução: Jess Oliveira. Rio de Janeiro: Cobogó, 2019.

LOURO, G. L. Um corpo estranho: Ensaios sobre sexualidade e teoria queer. Belo Horizonte: Autêntica Editora, 2018.

MENDES, A.In: GALDINO, Daniela (org.). Profundanças2. Ipiaú: Voo Audiovisual, 2017. p. 22. RIBEIRO, D. Quem tem medo do feminismo negro? São Paulo: Companhia das Letras, 2018.

SCHMIDT, R. T. Descentramento /convergências: ensaios de crítica feminista. Porto Alegra: UFRGS Editora, 2017.

SPIVAK, G. C. Pode o subalterno falar? Tradução de Sandra Regina Goulart Almeida, Marcos Pereira Feitosa, André Pereira Feitosa. Belo Horizonte: Editora UFMG, 2010.

\section{REFERÊNCIAS BIBLIOGRÁFICAS}

ALEMANY, C. Violências. Tradução: Naira Pinheiro. In: Dicionário Crítico do Feminismo. Org. Helena 
SANTOS DE MATOS, Elisiane; PEREIRA DO SACRAMENTO, Sandra Maria. Sou o sonho de humanidade que vocês esquecem: uma análise interseccional das opressões, a partir da poesia de Ana Mendes. Signo, Santa Cruz do Sul, v. 45, n. 84, nov. 2020. ISSN 1982-2014. Disponível em: <https://online.unisc.br/seer/index.php/signo/article/view/15598>.Doi:https://doi.org/10.17058/signo.v45i84. 15598. 